\title{
High IL-17 expression is associated with an unfavorable prognosis in thyroid cancer
}

\author{
DENISE FARIA GALANO CARVALHO ${ }^{1}$, BRUNA RIEDO ZANETTI ${ }^{1}$, LYDIANNE MIRANDA ${ }^{2}$, \\ MARCELA KAZUE HASSUMI-FUKASAWA ${ }^{1}$, FABIANA MIRANDA-CAMARGO ${ }^{1}$, \\ JANAÍNA CRISTIANA OLIVEIRA CRISPIM ${ }^{2}$ and EDSON GARCIA SOARES ${ }^{1}$ \\ ${ }^{1}$ Department of Pathology, Faculty of Medicine of Ribeirão Preto, University of São Paulo, São Paulo, \\ SP 14049-900; ${ }^{2}$ Laboratory of Immunopathology, Department of Clinical Analysis and \\ Toxicology, Federal University of Rio Grande do Norte, Natal, RN 59012-570, Brazil
}

Received April 8, 2015; Accepted August 25, 2016

DOI: $10.3892 / \mathrm{ol} .2017 .5638$

\begin{abstract}
Previous studies have indicated that cancer may be promoted and/or exacerbated by inflammation and infection. The cytokines produced by activated innate immune cells that stimulate tumor growth and progression are considered as important components in this process. The interleukin (IL)-23/T helper (Th)17 axis, which exerts marked pro-inflammatory effects, has emerged as an important mediator in inflammation-associated cancer. Increasing clinical evidence indicates that Th17 may promote or inhibit tumor progression, however, the function of Th17 in the pathogenesis of benign and malignant thyroid neoplasms remains unclear. The present study investigated the association between the IL-23/Th17 axis and neoplastic and non-neoplastic thyroid lesions using immunohistochemistry. A total of 131 thyroid biopsy specimens were analyzed, which revealed high IL-17 and IL-23 expression in differentiated thyroid cancer and medullary thyroid cancer tissues when compared with benign lesions, including follicular thyroid adenoma and goiter tissues. Furthermore, high IL-17 expression was associated with recurrence and mortality. These results indicate that the IL-23/Th17 axis exhibits a pivotal function in the development of thyroid neoplasms.
\end{abstract}

\section{Introduction}

The phenotypic diversity of immune cells in the tumor microenvironment may exhibit a positive or negative influence on tumor development and clinical outcome. The tumor microenvironment is composed of stromal, endothelial and innate cells, as

Correspondence to: Mr. Denise Faria Galano Carvalho or Mr. Bruna Riedo Zanetti, Department of Pathology, Faculty of Medicine of Ribeirão Preto, University of São Paulo, 3900 Avenida dos Bandeirantes, São Paulo, SP 14049-900, Brazil

E-mail: denisegalano@hotmail.com

E-mail: brunabrz@hotmail.com

Key words: thyroid cancer, goiter, immune response, interleukin-17, interleukin-23, clinical factors, immunohistochemistry well as lymphocytes, which interact to form a complex system that surrounds tumor cells $(1,2)$. The recruitment of immune effector cells to the tumor site and the intensity of specific responses are mediated by cytokines, which are secreted by immune system and tumor cells (3). Additionally, these cytokines are essential for the differentiation of all immune cell types in the tumor milieu (4). For an appropriate immune response against pathogens, adequate activation of naive $\mathrm{T}$ lymphocytes is required. The stimuli received by the immune system leads to the activation of a lymphocyte response, which is different for each antigen (5). In response to the stimulus provided by an antigen-presenting cell, a precursor T helper (Th) 0 lymphocyte may differentiate into a T helper type 1 cell (Th1), Th2, Th17 or a Foxp $3^{+}$regulatory $\mathrm{T}$ (Treg) cell, depending on the cytokines present in the microenvironment $(5,6)$. The Th1 profile, which promotes a pro-inflammatory immune response, is induced by interleukin (IL)-12 and tumor necrosis factor $\alpha$ (TNF- $\alpha)(7)$, whereas the Th2 profile, which promotes a humoral immune response, is initiated by IL-4 (8). Both Th1 and Th2 are involved in intensifying anti-tumor immunity by inducing the expansion of cytotoxic CD8+ T cell populations (6); however, Treg cells that are predominantly induced by IL-2, promote antitumor suppressor activity via the inhibition of CD8+ T cells $(5,9)$. The Th17 phenotype presents a distinct strain of CD4+ T cells that secrete important ILs, including IL-17A, IL-17F, IL-21 and IL-22. Differentiation of Th17 cells occurs in the presence of IL-6, IL-21 and tumor growth factor- $\beta$ (TGF- $\beta$ ), while their stability is maintained by IL- $1 \beta$ and IL-23 $(6,10)$. Although the Th17 profile is involved with increased immunity and host defenses, its involvement in neoplastic processes remains controversial $(6,10)$. Previous studies suggest that Th17 cells are involved in cancer promotion (11-15). Notably, in the tumor microenvironment, Th17 cells have been observed to positively correlate with immune effector cells, including CD8+ T cells and natural killer cells, promoting an antitumor response that is mediated by cytotoxic cells $(11,12)$. As a result of the production of pro-inflammatory cytokines by Th17 cells that accumulate in the tumor microenvironment, and the association between the development and progression of cancer, a positive correlation between these cells and disease progression has been hypothesized $(13,14)$. The presence of inflammatory cells and soluble 
factors in the tumor microenvironment has been demonstrated; however, predicting patient prognosis based on the presence of immune system cells is difficult as various organs react differently to certain cytokines (15). A number of studies have identified the presence of numerous tumor-associated lymphocytes in Hashimoto's thyroiditis, as well as in the absence of the typical symptoms of autoimmune thyroiditis (16-19). The effect of the Th17 profile, which includes immune cells, cytokines, chemokines and their receptors may be protective or act as a trigger for thyroid tumors, depending on the histological classification of the tumor (16). Notably, the presence of lymphocytic infiltrates in patients with PTC is higher than that in patients with benign lesions; however, PTC associated with thyroiditis exhibits a better prognosis $(17,18)$. Thyroid carcinomas with a poor prognosis, such as poorly-differentiated and anaplastic thyroid carcinomas, are characterized by a marked reduction in lymphocyte cell infiltrates compared with PTCs, which indicates that these cells may exhibit a protective function in thyroid cancer (19). Thyroid neoplasms are the most common type of endocrine tumor, worldwide, accounting for $1 \%$ of malignant neoplasms (20). Notably, the incidence rate of thyroid neoplasms has gradually increased in recent decades in a number of countries (21). Our previous study investigated the association between the immune system and thyroid tumors $(22,23)$ to determine whether certain molecules may be associated with different tumor subtypes and patient prognoses. Thus, considering the significant effect of IL-17 and the importance of IL-23 in maintaining the cellular Th17 response, evaluating the expression profile of these cytokines in lymphocytes and their distribution in neoplastic and non-neoplastic thyroid tissue is essential to understanding the complex association between the tumor microenvironment and the Th17 profile.

\section{Materials and methods}

Specimens. A total of 131 thyroid biopsy specimens collected between January 1999 and December 2012 were obtained from the archives of the Pathology Department, Faculty of Medicine of Ribeirão Preto (FMRP), University of São Paulo (São Paulo, Brazil). The specimens included 61 cases of papillary thyroid carcinoma (PTC), 19 cases of follicular thyroid carcinoma (FTC), 8 cases of medullary thyroid carcinoma (MTC), 22 cases of follicular thyroid adenoma (FTA) and 21 goiter biopsies, which represented non-neoplastic lesions. In addition, 9 normal thyroid tissue specimens, which were obtained from the Endocrinology Department of the University of São Paulo, were included as the control. The tissues corresponded to patients who had undergone surgery for thyroid cancer, which implies total or partial removal of the thyroid gland when the result of cytology is positive or suggestive. However, paraffin-embedded tissue from the hospital file or tumor bank were used in the present study. Tissues exhibiting no autolysis, artifacts or signs of inadequate processing during fixation were selected for the study. Biopsies obtained from patients who were human immunodeficiency virus positive, immunosuppressed or had previously undergone radiotherapy for the treatment of cancer were excluded. The carcinomas were staged based on the size of the tumor, lymph node metastases and distant metastases, according to the criteria defined by the American
Joint Committee on Cancer (2002) (24) and reviewed by the American Thyroid Association (25). Patient clinicopathological information, including age, gender, recurrence, metastases and mortality was obtained from the service records of the FMRP University Hospital (Table I). The study protocol was approved by the Brazilian Institutional Ethics Committee on Human Experimentation (1286/2011) (School of Medicine of Ribeirão Preto, University of São Paulo).

Immunohistochemistry. Tissue sections $(5-\mu \mathrm{m})$ were cut, placed on slides pretreated with organosilane and subjected to immunohistochemical assay using the avidin-biotin-peroxidase method with a universal Novostain Super ABC kit (Novocastra, Newcastle Upon Tyne, UK) to analyze IL-17 and -23 expression. Polyclonal rabbit anti-mouse IL-17 (1:200; cat. no. ab79056; Abcam, Cambridge, UK) and IL-23 (1:70; cat. no. ab45420; Abcam) were used as the primary antibodies. The sections were deparaffinized in xylene, rehydrated in alcohol with decreasing concentration and washed in water. For antigen retrieval, the sections were immersed in $10 \mathrm{mM}$ sodium citrate buffer ( $\mathrm{pH} 6.0$ ) at $95^{\circ} \mathrm{C}$ for $35 \mathrm{~min}$. Endogenous peroxidase activity was blocked following incubation with $3 \%$ hydrogen peroxide in phosphate-buffered saline (PBS) for $20 \mathrm{~min}$, and nonspecific binding was blocked following incubation with 1:50 horse serum [included in the Polymer Detection system Novolink kit (Novocastra)] in PBS for $30 \mathrm{~min}$. The slides were washed with PBS and incubated with IL-17 and IL-23 primary antibodies overnight in a humidified chamber at $4^{\circ} \mathrm{C}$ overnight. The final step was incubation for $15 \mathrm{~min}$ with probe (similar to a secondary antibody), followed by signal amplification of the reaction with polymer incubation for $30 \mathrm{~min}$, according to the protocol provided by the manufacturer of the Polymer Detection system Novolink kit. The samples were then incubated with 3,3'-diaminobenzidine (Gibco; Thermo Fisher Scientific, Inc., Waltham, MA, USA) diluted in $0.01 \% \mathrm{H}_{2} \mathrm{O}_{2}$ for $40 \mathrm{sec}$ and lightly counterstained with Harris' hematoxylin monohydrate (Merck Millipore, Darmstadt, Germany) for $60 \mathrm{sec}$. The sections were then rehydrated in absolute alcohol and xylene, and the slides were mounted using Permount mounting medium (Merck Millipore) and visualized by microscopy with Image Pro Plus software (Media Cybernetics, Inc., Rockville, MD, USA).

Immunohistochemical evaluation. The semi-quantitative evaluation of IL-17 and IL-23 expression was based on the proportion of positive cells within the tumors. To determine the proportion of positive cells in the tissue specimens, a score was calculated based on the mean basal expression observed in normal thyroid tissues (controls). The mean basal expression of control tissues was performed by evaluating with an optical microscope the staining of 10 different fields in the same slide. Qualitative analysis was determined by the intensity of staining. Samples without expression or with low intensity of staining were considered low-expression specimens, while samples with moderate or severe staining intensity were considered as high-expression specimens. The mean basal expression rates were 20 and $24 \%$ for IL-17 and IL-23, respectively. These values were used as the cutoff points to define subgroups exhibiting low and high expression of IL-17 and IL-23 in the tumor tissues. The amount and distribution of positive lymphocytes between tumor cells as well as around adjacent tumor were evaluated from the mean intensity 
Table I. Association between IL-17 and IL-23 expression and clinicopathological parameters in malignant differentiated and medullary thyroid carcinoma patients.

\begin{tabular}{|c|c|c|c|c|c|c|}
\hline \multirow[b]{2}{*}{ Parameter } & \multicolumn{2}{|c|}{ IL-17 expression } & \multirow[b]{2}{*}{ P-value } & \multicolumn{2}{|c|}{ IL-23 expression } & \multirow[b]{2}{*}{ P-value } \\
\hline & Low, $\mathrm{n}$ & High, $n$ & & Low, $\mathrm{n}$ & High, $n$ & \\
\hline Age, years & & & 0.8345 & & & 1.0000 \\
\hline$\leq 45$ & 20 & 23 & & 9 & 34 & \\
\hline$>45$ & 22 & 23 & & 9 & 36 & \\
\hline Gender & & & 0.6275 & & & 0.2197 \\
\hline Female & 33 & 34 & & 16 & 51 & \\
\hline Male & 9 & 12 & & 2 & 19 & \\
\hline Tumor size, cm & & & 0.2832 & & & 0.1560 \\
\hline$\leq 2$ & 12 & 20 & & 6 & 26 & \\
\hline$>2-4$ & 22 & 17 & & 11 & 28 & \\
\hline$\geq 4$ & 8 & 9 & & 1 & 16 & \\
\hline Metastasis & & & 0.4914 & & & 0.9971 \\
\hline Ganglionic & 10 & 10 & & 4 & 16 & \\
\hline Distant & 3 & 7 & & 2 & 8 & \\
\hline None & 29 & 29 & & 12 & 46 & \\
\hline Histological grade & & & 0.9443 & & & 0.9945 \\
\hline I-II & 25 & 29 & & 11 & 43 & \\
\hline III & 10 & 10 & & 4 & 16 & \\
\hline IV & 7 & 7 & & 3 & 11 & \\
\hline Recurrence/Mortality & & & 0.0376 & & & 1.0000 \\
\hline No & 38 & 31 & & 14 & 55 & \\
\hline Yes & 5 & 14 & & 4 & 15 & \\
\hline
\end{tabular}

$\chi^{2}$ test and Fisher's exact test were performed to assess the significant differences between clinicopathological parameters and IL-17 and IL-23 expression. IL, interleukin.

of immunostaining. Histological sections of laryngeal tissues with epithelial invasive carcinoma served as the positive controls.

Statistical analysis. For statistical analyses, the carcinomas were grouped according to their histological characteristics. Comparisons were performed between the following groups: Differentiated thyroid carcinoma [(DTC) including PTCs and FTCs) (malignant neoplasm), MTC (malignant neoplasm), FTA (benign neoplasm) and goiter (non-neoplastic lesion) tissues. Fisher's exact test was used to compare two groups of data and the $\chi^{2}$ test was used to analyze differences between more than three groups. Kruskal-Wallis test with Dunn's post-hoc test was used to compare the mean expression of IL-17 and IL-23 in the lymphocytes among thyroid lesions. Spearmen's rank correlation analysis was used to assess the correlation between these parameters. $\mathrm{P}<0.05$ was considered to indicate a statistically significant difference. All statistical analyses were performed using Graph Pad Prism 5.0 software (GraphPad Software, Inc., La Jolla, CA, USA).

\section{Results}

IL-17 expression. The expression of IL-17 was compared between different thyroid lesions. IL-17 positive cells were identified in both tumor tissues and in adjacent non-tumoral lymphocytic tissues. The expression of IL-17 expression was quantified according to the mean expression exhibited in normal thyroid tissue (Fig. 1). The mean [ \pm standard deviation (SD)] IL-17 expression rate of normal thyroid tissue was $20 \pm 9.3 \%$. Thus, tissues exhibiting IL-17 expression rates of $<20$ and $\geq 20 \%$ were defined as low and high expression groups, respectively. Semi-quantitative analyses revealed that neoplastic lesions exhibited significantly increased IL-17 expression rates compared with non-neoplastic lesions (Table II). The results revealed a higher percentage of cells expressed positivity for IL-17 in the DTC (100\%), MTC (100\%) and FTA (95.4\%) groups compared with the goiter group (52.4\%). The mean $( \pm \mathrm{SD})$ IL-17 expression rates were $82.1 \pm 9.9,75 \pm 20.7,69.1 \pm 19$ and $33.8 \pm 18.6 \%$ in DTC, MTC, FTA and goiter tissues, respectively. The following mean $( \pm \mathrm{SD}) \mathrm{IL}-17$ expression rates of the lymphocytic infiltrates of DTC, MTC and FTA tissues were 35.6 $\pm 13.1,43.8 \pm 15.1$ and $27.7 \pm 10.7 \%$, respectively. In the goiter group, the mean $( \pm$ SD) IL-17 expression rate of the lymphocytic infiltrate cells was $20.9 \pm 17 \%$, which was significantly lower than that of the DTC $(\mathrm{P}<0.0001)$, FTA $(\mathrm{P}=0.0015)$ and MTC $(\mathrm{P}=0.0265)$ groups. However, no significant differences in the IL-17 expression rate of the lymphocytic infiltrates were identified between the 
Table II. IL-17 expression in neoplastic and non-neoplastic thyroid lesions $(\mathrm{n}=131)$.

\begin{tabular}{lccc}
\hline & Low IL-17 expression & High IL-17 expression & \\
\cline { 2 - 3 } Thyroid tissue & $\mathrm{n}(\%)$ & $80(100)$ & P-value \\
\hline DTC & $0(0)$ & $8(100)$ & $0.2157^{\mathrm{a}} /<0.0001^{\mathrm{b}}$ \\
MTC & $0(0)$ & $21(95.4)$ & $1.0000^{\mathrm{c}} / 0.02650^{\mathrm{d}}$ \\
FTA & $1(4.6)$ & $11(52.4)$ & $0.0015^{\mathrm{e}}$ \\
Goiter & $10(47.6)$ & $0.0015^{\mathrm{e}}$
\end{tabular}

Fisher's exact test was used to compare the groups. ${ }^{a}$ DTC vs. FTA. ${ }^{b}$ DTC vs. goiter. ${ }^{c}$ MTC vs. FTA. ${ }^{d}$ MTC vs. goiter. ${ }^{e}$ FTA vs. goiter. Low and high IL-17 expression in tissues was defined as $<$ and $\geq 20 \%$ of positively stained cells, respectively. IL, interleukin; DTC, differentiated thyroid carcinoma; MTC, medullary thyroid carcinoma; FTA, follicular thyroid adenoma.
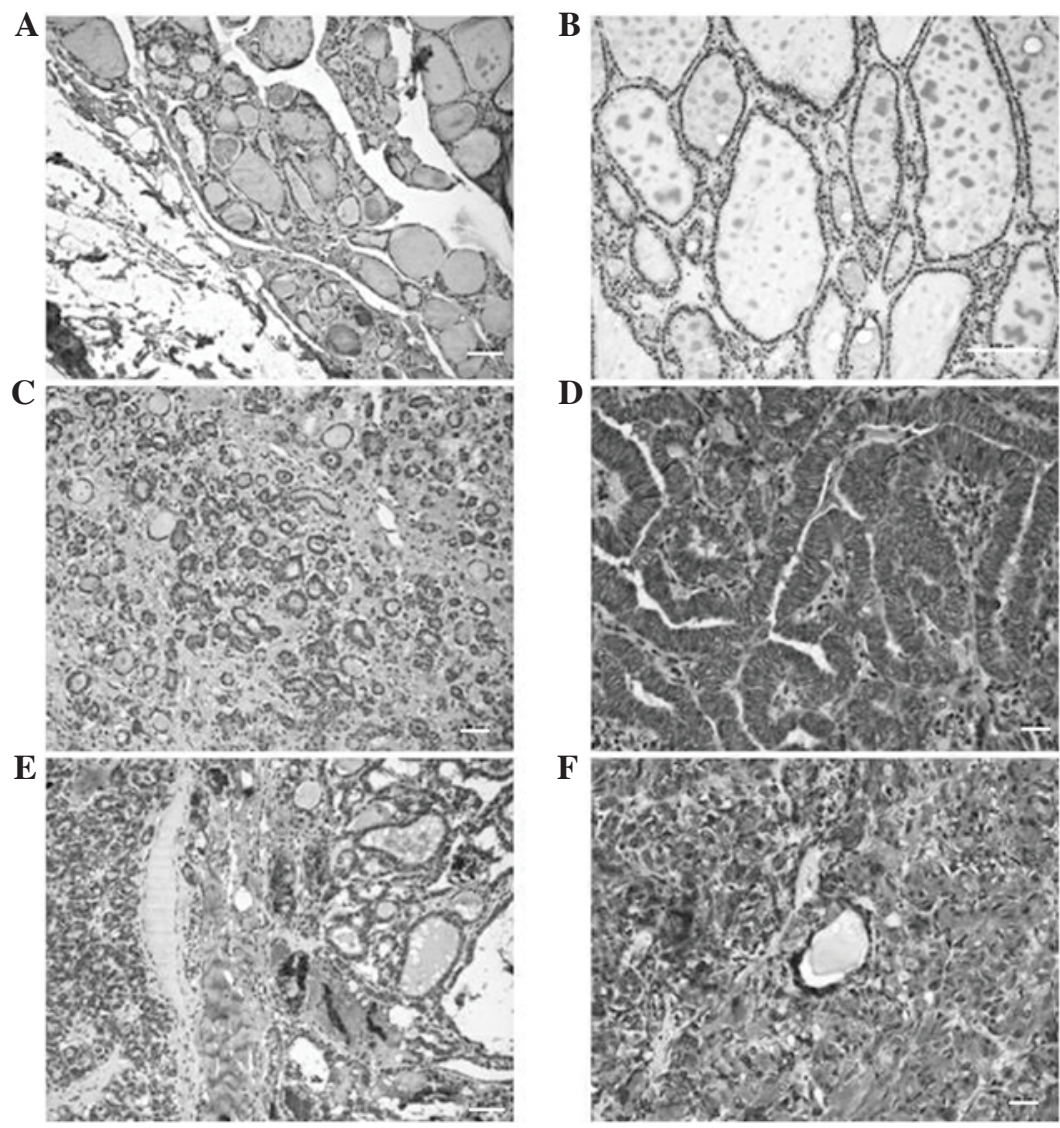

Figure 1. Interleukin-17 expression determined by immunohistochemistry. (A) Normal thyroid tissue. (B) Low expression in colloid goiter tissue. (C) Low expression in follicular thyroid adenoma. (D) High expression in papillary thyroid carcinoma. (E) High expression in follicular thyroid carcinoma. (F) High expression in medullary thyroid carcinoma. Scale bar $=50 \mu \mathrm{M}$.

neoplastic tissues. Kruskal-Wallis test with Dunn's post-hoc test revealed significant differences in IL-17 expression of the labeled lymphocytes between the malignant neoplasm groups and the goiter group (DTC vs. goiter, $\mathrm{P}<0.001$; MTC vs. goiter, $\mathrm{P}<0.01)$. A significant correlation between the mean IL-17 expression rate was identified between the tumor cells and adjacent lymphocytes in MTC tissues $(\mathrm{P}=0.0072)$.

IL-23 expression. The expression of IL-23 was quantified according to the mean expression exhibited in normal thyroid tissue (Fig. 2). The mean [ \pm standard deviation (SD)] IL-23 expression rate of normal thyroid tissue was $24 \pm 22.4 \%$. Thus, tissues exhibiting IL-23 expression rates of $<24$ and $\geq 24 \%$ were defined as low and high expression groups, respectively. Analysis reveled that IL-23 expression rates were significantly higher in the neoplastic groups when compared with the goiter group. As shown in Table III, a significant difference in IL-23 expression was identified between the goiter (benign lesion) group and the DTC (malignant neoplasm) group $(\mathrm{P}<0.0001)$, as well as the FTA (benign neoplasm) group ( $\mathrm{P}=0.0212)$. These results also revealed that a higher percentage of DTC (100\%), MTC (100\%) and FTA (95.4\%) cases exhibited high IL-23 expression compared with the goiter group (66.7\%). The mean $( \pm \mathrm{SD}) \mathrm{IL}-23$ expression rates of the labeled cells 
Table III. IL-23 expression in neoplastic and non-neoplastic thyroid lesions $(n=131)$.

\begin{tabular}{lccc}
\hline & Low IL-23 expression & & High IL-23 expression \\
\cline { 2 - 3 } Thyroid tissue & $\mathrm{n}(\%)$ & $\mathrm{n}(\%)$ & $0.2157^{\mathrm{a} /}<0.0001^{\mathrm{b}}$ \\
\hline DTC & $0(0)$ & $80(100)$ & $1.0000^{\mathrm{c}} / 0.1421^{\mathrm{d}}$ \\
MTC & $0(0)$ & $8(100)$ & $0.0212^{\mathrm{e}}$ \\
FTA & $1(4.6)$ & $21(95.4)$ & $0.0212^{\mathrm{e}}$ \\
Goiter & $7(33.3)$ & $14(66.7)$ & $0 . \mathrm{C}$ \\
\hline
\end{tabular}

Fisher's exact test was used to compare the groups. ${ }^{a}$ DTC vs. FTA. ${ }^{b}$ DTC vs. goiter. ${ }^{c}$ MTC vs. FTA. ${ }^{d}$ MTC vs. goiter. ${ }^{e}$ FTA vs. goiter. Low and high IL-23 expression in tissues was defined as $<$ and $\geq 24 \%$ of positively stained cells, respectively. IL, interleukin; DTC, differentiated thyroid carcinoma; MTC, medullary thyroid carcinoma; FTA, follicular thyroid adenoma.

A
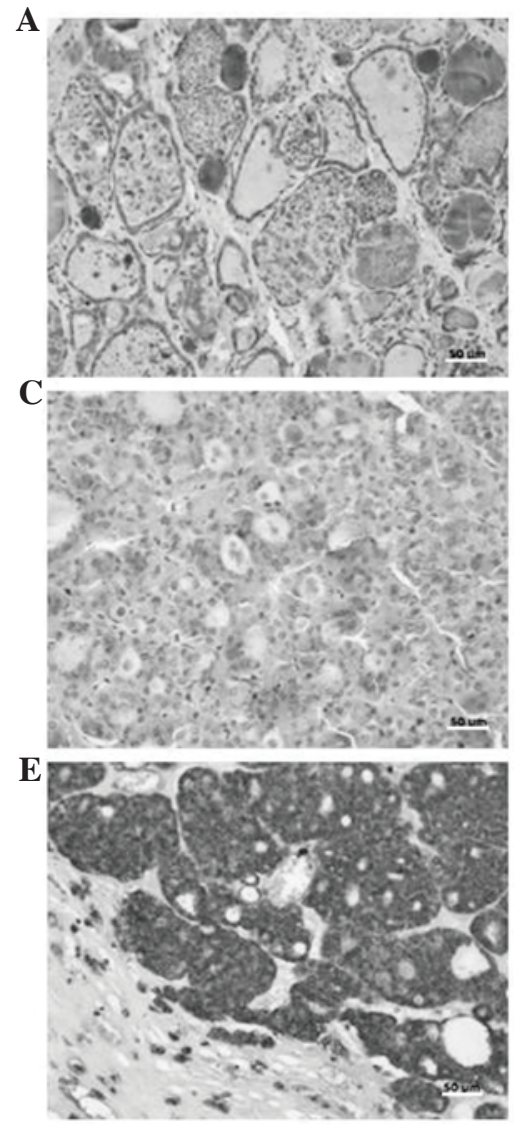

B

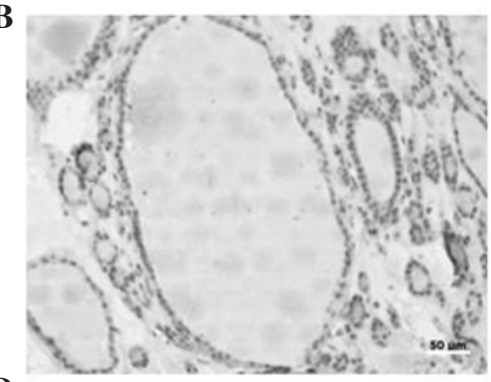

D
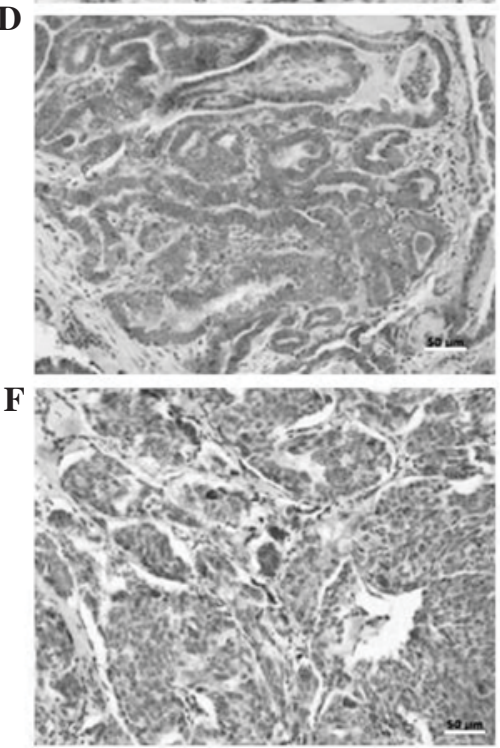

Figure 2. Interleukin-23 expression determined by immunohistochemistry. (A) Normal thyroid tissue. (B) Low expression in colloid goiter tissue. (C) Low expression in follicular thyroid adenoma. (D) High expression in papillary thyroid carcinoma. (E) High expression in follicular thyroid carcinoma. (F) High expression in medullary thyroid carcinoma. Scale bar $=50 \mu \mathrm{M}$.

were $89.2 \pm 11.8,89 \pm 9.9,76 \pm 19.6$ and $44 \pm 26.4 \%$ in the DTC, MTC, FTA and goiter groups, respectively. The mean staining of the tumor microenvironment lymphocytes was more homogeneous in the tumors studied (DTC, $32 \pm 15$ and MTC, $31 \pm 14)$. However, the mean of the labeled lymphocytes was lowest $(19 \pm 14)$ in the goiter group. Kruskal-Wallis test with Dunn's post hoc test revealed significant differences in IL-23 expression of the labeled lymphocytes between the malignant neoplasm group (DTC) and the goiter group (DTC vs. goiter, $\mathrm{P}<0.001)$. A significant positive correlation was identified between the mean IL-23 expression rate in the thyroid lesion cells and their microenvironment lymphocytes in the DTC $(\mathrm{P}=0.0252)$, FTA $(\mathrm{P}=0.0015)$ and goiter $(\mathrm{P}=0.0002)$ groups.

IL-17 expression is associated with poor outcomes in DTC and MTC. The associations between IL-17 and IL-23 expression and clinicopathological parameters were evaluated (Table I). The results revealed that IL-17 expression was associated with recurrence/mortality $(\mathrm{P}=0.0376)$. Notably, of the 69 patients that exhibited no recurrence or mortality, $45 \%$ (31/69) exhibited high IL-17 expression, whereas in the patient group that exhibited recurrence or mortality, $74 \%$ of 
patients (14/19) exhibited high IL-17 expression. No significant associations were identified between IL-23 expression and any of the clinicopathological parameters evaluated.

$I L-17$ and $I L-23$ expression is positively correlated in DTC tissues. A positive correlation between IL-17 and IL-23 expression was identified in the DTC group ( $\mathrm{P}=0.0112)$. However, no significant correlation was identified between IL-17 and IL-23 expression in the MTC, FTA or goiter groups.

\section{Discussion}

Increasing evidence suggests that tumorigenesis results from chronic inflammation (26), which involves cytokine and chemokine networks that have been extensively studied to provide novel therapies against cancer (27). The association between DTC and thyroiditis, which affects the thyroid gland, is frequently cited as evidence of this theory (28). In this type of association, a mixture of macrophages and lymphocytes is observed in the tumor microenvironment, thus supporting the hypothesis that the immune response can influence thyroid cancer progression (29). IL-17 is a cytokine produced by a subset of lymphocytes known as Th17 cells. IL-17 is involved in the initial activation of the immune system and exhibits an important function in the interaction between the innate and adaptive immune response. Since IL-17 is involved in the pathogenesis of chronic inflammatory responses and is known to induce the production of high concentrations of IL- $1 \beta$, TNF- $\alpha$, TGF- $\beta$, CC chemokine ligand (CCL) 2 and matrix metalloproteinase mediators that are widely found in the tumor microenvironment (30), this cytokine presents a potential target that requires investigation.

In the present study, immunohistochemical analysis revealed that all cells were positive for IL-17 and IL-23 in all thyroid tumor types evaluated, as well as in the lymphocytes surrounding the lesions. These findings indicate a significant association between the Th17 profile and thyroid neoplasms. Due to its strong presence in the tumor microenvironment, it is hypothesized that IL-17 functions in the early stages of tumorigenesis. An increase in IL-17 expression triggers the release of IL-6 inflammatory cytokines and consequently the activation of signal transducer and activator of transcription 3 (STAT3) and necrosis factor kappa $\beta$, which are associated with the production of pro-inflammatory cytokines. The tumor cells are capable of perpetuating the local inflammatory response via the expression of CCL2, which stimulates the monocyte secretory IL-17 input, contributing to inflammation and tumor growth $(31,32)$. Additionally, STAT3 is regulated by IL-23, which promotes a protumor activity cascade and the presence of IL-23 stabilizes Th17 cells (33). In the present study, the expression of IL-17 protein was decreased in the biopsies of benign lesions (FTA and goiter tissues) when compared to malignant lesions (DTC and MTC). We hypothesize that the increased cytokine expression in the tumor environment may be associated with tumor progression, which is in agreement with the findings of Su et al (34) who demonstrated that a high number of CD4+ Th17 cells were present in melanoma, ovarian, breast and colon carcinomas (34). In the present study, the lymphocytes present in the tumor microenvironment of the MTC group tumors expressed the highest level of IL-17 expression compared with the DTC, FTA and goiter groups. In addition, a positive correlation was identified between IL-17 expression in tumor cells and adjacent lymphocytes in the MTC group. Notably, MTC patient exhibited the worst disease outcome; therefore, we postulate that the presence of IL-17-producing lymphocytes may influence disease progression. Similar to the results of IL-17, analysis of IL-23 expression revealed that a significant number of neoplastic cells exhibited high IL-23 protein expression, which was not observed in goiter tissues. IL-23 is a heterodimeric cytokine belonging to the IL-12 family that consists of 2 subunits, p40 (shared with IL-12) and p19 $(35,36)$. This cytokine signals via a specific receptor consisting of the IL-12 receptor (R) chain and the IL-23R chain (37). Notably, IL-23 is required for the survival of Th17 cells (38). In the present study, a positive correlation between the expression of IL-17 and IL-23 was identified in the DTC group, which may indicate explain the presence of functional Th17 in the microenvironment of DTC injury tissues, which is in agreement with the literature. A number of studies have demonstrated that IL-17 induces vascular endothelial growth factor expression, which subsequently induces TGF- $\beta$ (37-39). Numerous tumor cells express high levels of TGF- $\beta$, which promotes tumor growth and metastasis (39). The effect of TGF- $\beta$ in the differentiation of $\mathrm{CD} 4+\mathrm{T}$ cells may be influenced by the cytokines present in the tumor microenvironment. For example, IL-23 is able to induce IL-17 production by memory and activated $\mathrm{T}$ cells and is essential for the development, survival and growth of these cells $(40,41)$. In the present study, the differential expression of IL-17 and IL-23 between malignant and benign lesions indicates that the presence or absence of these cytokines may influence disease progression. Therefore, the Th-17/IL-23 axis may facilitate the malignant progression of cancer and the association between IL-17 and IL-23 in the microenvironment indicates that the two molecules may interact. The exact mechanism underlying this interaction remains unclear; however; we hypothesize that these molecules are important in the progression of cancer. Th17 cells have been identified in a number of human tumor types, including lymphoma (40), myeloma (41), breast (34) and ovarian cancer (42). In colorectal carcinomas, prognosis is influenced by Th17 expression; patients with high Th17 expression exhibit a poor prognosis (43). Zhang et al (44) demonstrated that the accumulation of IL-17-producing cells in the tumor microenvironment leads to tumor progression in patients with hepatocellular carcinoma by promoting angiogenesis. In the present study, of the 19 patients who experienced recurrence or succumbed to the disease, 14 (73.4\%) exhibited high IL-17 protein expression, which indicates that the IL-17 cytokine is involved in the development and progression of tumors, and thus may present a prognostic factor for poor survival. These results indicate an association between infiltration of Th17 cells and poor prognosis, which confirms that Th17 may inhibit antitumor responses. Based on these results, we postulate that the growth and progression of thyroid cancer may be positively influenced by two major inflammatory components, IL-17 and IL-23.

\section{Acknowledgements}

The present study was supported by the National Council of Scientific and Technological Development Process of Brazil (grant no. HCRP 3156/2011). The authors would like to thank Ms. Ana Maria Rocha (Department of Pathology, Faculty of Medicine of Ribeirão Preto, University of São Paulo, São Paulo, Brazil) for her technical assistance. 


\section{References}

1. Talmadge JE, Donkor M and Scholar E: Inflammatory cell infiltration of tumors: Jekyll or Hyde. Cancer Metastasis Rev 26: 373-400, 2007

2. Qi W, Huang X and Wang J: Correlation between Th17 cells and tumor microenvironment. Cell Immunol 285: 18-22, 2013.

3. Talmadge JE: Immune cell infiltration of primary and metastatic lesions: Mechanisms and clinical impact. Semin Cancer Biol 21: 131-138, 2011.

4. Coussens LM and Werb Z: Inflammation and cancer. Nature 420: 860-867, 2002.

5. Josefowicz SZ, Lu LF and Rudensky AY: Regulatory T cells: Mechanisms of differentiation and function. Annu Rev Immunol 30: 531-564, 2012

6. Bailey SR, Nelson MH, Himes RA, Li Z, Mehrotra S and Paulos CM: Th17 cells in cancer: The ultimate identity crisis. Front Immunol 5: 276, 2014.

7. Chen $\mathrm{Z}$ and O'Shea JJ: Th17 cells: A new fate for differentiating helper T cells. Immunol Res 41: 87-102, 2008

8. Peck A and Mellins ED: Plasticity of T-cell phenotype and function: The T helper type 17 example. Immunology 129: $147-153,2010$

9. Barbi J, Pardoll D and Pan F: Treg functional stability and its responsiveness to the microenvironment. Immunol Rev 259 $115-139,2014$

10. Stritesky GL, Yeh N and Kaplan MH: IL-23 promotes maintenance but not commitment to the Th17 lineage. J Immunol 181 5948-5955, 2008

11. Kryczek I, Banerjee M, Cheng P, Vatan L, Szeliga W, Wei S, Huang E, Finlayson E, Simeone D, Welling TH, et al: Phenotype, distribution, generation and functional and clinical relevance of Th17 cells in the human tumor environments Blood 114: 1141-1149, 2009.

12. Azzazene D, Al Thawadi H, Al Farsi H, Besbes S, Geyl C, Mirshahi S, Pardo J, Faussat AM, Jeannette S, Therwath A, et al: Plasma endothelial protein $C$ receptor influences innate immune response in ovarian cancer by decreasing the population of natural killer and TH17 helper cells. Int J Oncol 43: 1011-1018, 2013.

13. Muranski P, Boni A, Antony PA, Cassard L, Irvine KR, Kaiser A, Paulos CM, Palmer DC, Touloukian CE, Ptak K, et al: Tumor-specific Th17-polarized cells eradicate large established melanoma. Blood 112: 362-373, 2008.

14. Sfanos KS, Bruno TC, Maris $\mathrm{CH}, \mathrm{Xu} \mathrm{L}$, Thoburn CJ, DeMarzo AM, Meeker AK, Isaacs WB and Drake CG: Phenotypic analysis of prostate-infiltrating lymphocytes reveals TH17 and Treg skewing. Clin Cancer Res 14: 3254-3261, 2008.

15. Demaria S, Pikarsky E, Karin M, Coussens LM, Chen YC, El-Omar EM, Trinchieri G, Dubinett SM, Mao JT, Szabo E, et al: Cancer and inflammation: Promise for biologic therapy. $\mathrm{J}$ Immunother 33: 335-351, 2010.

16. Guarino V, Castellone MD, Avilla E and Melillo RM: Thyroid cancer and inflammation. Mol Cell Endocrinol 321: 94-102, 2010.

17. Okayasu I: The relationship of lymphocytic thyroiditis to the development of thyroid carcinoma. Endocr Pathol 8: 225-230, 1997.

18. Kebebew E, Treseler PA, Ituarte PH and Clark OH: Coexisting chronic lymphocytic thyroiditis and papillary thyroid cancer revisited. World J Surg 25: 632-637, 2001.

19. Ugolini C, Basolo F, Proietti A, Vitti P, Elisei R, Miccoli P and Toniolo A: Lymphocyte and immature dendritic cell infiltrates in differentiated, poorly differentiated, and undifferentiated thyroid carcinoma. Thyroid 17: 389-393, 2007.

20. Wang Y and Wang W: Increasing incidence of thyroid cancer in Shanghai, China, 1983-2007. Asia Pac J Public Health 27: 223-229, 2015.

21. Nikiforov YE: Molecular diagnostics of thyroid tumors. Arch Pathol Lab Med 135: 569-577, 2011.

22. Zanetti BR, Carvalho-Galano DF, Feitosa NL, Hassumi-Fukasawa MK, Miranda-Camargo FA, Maciel LM, Ribeiro-Silva A and Soares EG: Differential expression of immune-modulatory molecule HLA-E in non-neoplastic and neoplastic lesions of the thyroid. Int J Immunopathol Pharmacol 26 : 889-896, 2013

23. de Figueiredo Feitosa NL, Crispim JC, Zanetti BR, Magalhães PK, Soares CP, Soares EG, Neder L, Donadi EA and Maciel LM: HLA-G is differentially expressed in thyroid tissues. Thyroid 24 : 585-592, 2014.
24. Edge SB and Compton CC: The American Joint Committee on Cancer: The 7th edition of the AJCC cancer staging manual and the future of TNM. Ann Surg Oncol 17: 1471-1474, 2010.

25. American Thyroid Association (ATA) Guidelines Taskforce on Thyroid Nodules and Differentiated Thyroid Cancer; Cooper DS, Doherty GM, Haugen BR, Kloos RT, Lee SL, Mandel SJ, Mazzaferri EL, McIver B, Pacini F, Schlumberger M, et al: Revised American Thyroid Association management guidelines for patients with thyroid nodules and differentiated thyroid cancer. Thyroid 19 1167-1214, 2009.

26. Balkwill $\mathrm{F}$ and Mantovani A: Inflammation and cancer: Back to Virchow? Lancet 357: 539-545, 2001.

27. Landskron G, De la Fuente M, Thuwajit P, Thuwajit $C$ and Hermoso MA: Chronic inflammation and cytokines in the tumor microenvironment. J Immunol Res 2014: 149185, 2014

28. Muzza M, Degl'Innocenti D, Colombo C, Perrino M, Ravasi E, Rossi S, Cirello V, Beck-Peccoz P, Borrello MG and Fugazzola L: The tight relationship between papillary thyroid cancer, autoimmunity and inflammation: Clinical and molecular studies. Clin Endocrinol (Oxf) 72: 702-708, 2010.

29. French JD, Weber ZJ, Fretwell DL, Said S, Klopper JP and Haugen BR: Tumor-associated lymphocytes and increased FoxP3+ regulatory $\mathrm{T}$ cell frequency correlate with more aggressive papillary thyroid cancer. J Clin Endocrinol Metab 95: 2325-2333, 2010.

30. Ouyang W, Kolls JK and Zheng Y: The biological functions of T helper 17 cell effector cytokines in inflammation. Immunity 28 : 454-467, 2008.

31. Yang B, Kang H, Fung A, Zhao H, Wang T and Ma D: The role of interleukin 17 in tumour proliferation, angiogenesis, and metastasis. Mediators Inflamm 2014: 623759, 2014

32. Mizutani K, Sud S, McGregor NA, Martinovski G, Rice BT, Craig MJ, Varsos ZS, Roca H and Pienta KJ: The chemokine CCL2 increases prostate tumor growth and bone metastasis through macrophage and osteoclast recruitment. Neoplasia 11: 1235-1242, 2009.

33. Ngiow SF, Teng MW and Smyth MJ: A balance of interleukin-12 and -23 in cancer. Trends Immunol 34: 548-555, 2013.

34. Su X, Ye J, Hsueh EC, Zhang Y, Hoft DF and Peng G: Tumor microenvironments direct the recruitment and expansion of human Th17 cells. J Immunol 184: 1630-1641, 2010.

35. Kastelein RA, Hunter CA and Cua DJ: Discovery and biology of IL-23 and IL-27: Related but functionally distinct regulators of inflammation. Annu Rev Immunol 25: 221-242, 2007.

36. Stritesky GL, Yeh N and Kaplan MH: IL-23 promotes maintenance but not commitment to the Th17 lineage. J Immunol 181: 5948-5955, 2008.

37. Jeon SH, Chae BC, Kim HA, Seo GY, Seo DW, Chun GT, Kim NS, Yie SW, Byeon WH, Eom SH, et al: Mechanisms underlying TGF-beta1-induced expression of VEGF and Flk-1 in mouse macrophages and their implications for angiogenesis. J Leukoc Biol 81: 557-566, 2007.

38. Langowski JL, Zhang X, Wu L, Mattson JD, Chen T, Smith K, Basham B, McClanahan T, Kastelein RA and Oft M: IL-23 promotes tumour incidence and growth. Nature 442: 461-465, 2006.

39. Chizzolini C, Chicheportiche R, Alvarez M, de Rham C Roux-Lombard P, Ferrari-Lacraz S and Dayer JM: Prostaglandin E2 synergistically with interleukin-23 favors human Th17 expansion. Blood 112: 3696-3703, 2008.

40. Galand C, Donnou S, Crozet L, Brunet S, Touitou V, Ouakrim H, Fridman WH, Sautès-Fridman $\mathrm{C}$ and Fisson S: Th17 cells are involved in the local control of tumor progression in primary intraocular lymphoma. PLoS One 6: e24622, 2011.

41. Noonan K, Marchionni L, Anderson J, Pardoll D, Roodman GD and Borrello I: A novel role of IL-17-producing lymphocytes in mediating lytic bone disease in multiple myeloma. Blood 116 3554-3563, 2010.

42. Charles KA, Kulbe H, Soper R, Escorcio-Correia M, Lawrence T, Schultheis A, Chakravarty P, Thompson RG, Kollias G, Smyth JF, et al: The tumor-promoting actions of TNF-alpha involve TNFR1 and IL-17 in ovarian cancer in mice and humans. J Clin Invest 119: 3011-3023, 2009.

43. Tosolini M, Kirilovsky A, Mlecnik B, Fredriksen T, Mauger S, Bindea $G$, Berger A, Bruneval P, Fridman WH, Pagès F and Galon J: Clinical impact of different classes of infiltrating T cytotoxic and helper cells (Th1, th2, treg, th17) in patients with colorectal cancer. Cancer Res 71: 1263-1271, 2011.

44. Zhang JP, Yan J, Xu J, Pang XH, Chen MS, Li L, Wu C, Li SP and Zheng L: Increased intratumoral IL-17-producing cells correlate with poor survival in hepatocellular carcinoma patients. J Hepatol 50: 980-989, 2009. 